\title{
Training of high-rise engineers in light of the technical innovations of the XXI century
}

\author{
Igor Pryadko ${ }^{*}$ and Igor Lebedev ${ }^{1}$ \\ ${ }^{1}$ Moscow State University of Civil Engineering, Yaroslavskoe shosse, 26, Moscow, 129337, Russia
}

\begin{abstract}
In this article, the authors analyze the evaluations of the use of innovative methods of training of specialists in the construction of highrise buildings, made by those who himself is going to become a civil engineer. Such methods are proposed by the currently introduced educational standards in Russia (FSES 3 and $3+$ ). And thanks to familiarity with innovative technologies, the professionals will develop the ability to effectively use the existing urban area. In the article the authors give the conclusions of the specialists. In accordance with them the acquaintance of future builders with modern innovations will teach them to carry out a visual accentuation within the urban architectural and planning space. During the training at the bachelor's level, it is necessary to take into account the variety of functions of high-rise buildings, and discipline Cityplanning activity should be included in the course of studying disciplines, what the authors consideras the main innovation in construction of the XXI century. Within the discipline City-planning activity the vertical zoning is mandatory. In the article the authors rely on the data of the sociological survey conducted among students of the university of construction profile. In the discussion part of the article, the persons who chose the profession of civil engineer, builder of high-rise buildings, assessed the reforms of modern Russian education. In the course of the survey, the attitude of students of civil engineering to disciplines of social and legal profile is revealed.
\end{abstract}

\section{Introduction}

The issues of management of urban economy and construction are closely related to each other, that makes urban and municipal management of a complex, innovation-related field of activity. This despite the fact that a modern city is growing up and there is a distribution of energy flows, matter and information along the vertical. The latter forces city planners to make wide use of innovative technologies. And such innovations should be taught already at the stage of training of civil engineers (compare [1] [2] [3]). This position, shared by many people today, led the authors of the article to address the topic of training of high-rise builders, which is carried out at the Moscow State University of Civil Engineering.

The increase of the prestige of engineering and scientific and technical high-intellectual labor in the world market is noted today by many researchers. Particular attention is paid to

${ }^{*}$ Corresponding author: Priadcko.igor2011@yandex.ru 
the training of civil engineers in the field of high-rise construction. High-rise construction has recently become the sphere of application of the most advanced, sometimes unthinkable technical innovations.However, in our country both the increase of the prestige of engineering labor and the introduction of innovations in various spheres of civil engineering are not quick enough, and sometimes even unevenly [4][5]. With a significant advance, new technologies are being introduced into the field of high-rise buildings. This fact, which city planners and economists write about, we can explain by the expected revival in the investment and construction business and the accompanying increase in the attractiveness of the status and wages of the specialists engaged in construction [6] [7]. Similar innovations are observed in other countries. Some aspects of the problem of training civil engineers in domestic universities and in educational institutions in the field of highrise construction are discussed in the article below.

The training of specialists in high-rise construction has its own specifics. After all, it is necessary to calculate the construction of trusses of high-rise towers, take into account the requirements of "green construction" [8], with which the specialists are trying today to combine the erection of buildings of high storeys, to establish high-speed elevators, to establish the mode of their operation, to determine the zoning of the areas of erected buildings vertically, to take into account existing urbanspaces and, in general, learn to innovate.Among civil engineers, specialists in the design of high-rise buildings are highly respected, and there is a high demand in the labor market for such specialists, as the most qualified and trained engineers and architects. It is enough to specify the article [9], which refers to the degree of satisfaction of the heads of construction firms with specialists who are trained at the faculties ICC (Industrial and Civil Construction) of institutes of construction profile.

The acquaintance of future builders of high-rise buildings with innovative technologies takes place at the stage of training bachelors [10] [11]. Despite the fact that modern megacities grow vertically, and the concept of a "vertical city" continues to be one of the most promising models of cities of the future, the high-rise buildings and constructions are still classified as "unique".Meanwhile, the departments of construction universities, where specialists in the field of high-rise constructionare being trained, continue to undergo reorganizations, and educational programs are being brought up to the new, also in their own innovative educational standards. Within the framework of the Russian higher school, such standards are FSES 3 and 3+. The main innovation characteristic of the new standards is the competence approach, consistently conducted in them. Critics of innovations emphasize that this approach is being implemented at the expense of theoretical training. Namely, the knowledge of theories has always distinguished the engineers of high-rise construction.

Nowadays, in connection with Russia's accession to the Bologna process, the higher construction education passes to an innovative two-level system: a bachelor's degree with 4-years of study in the "ICC" profile and 5-years of study in the "Architecture" profile, as well as a master's program, correspondingly 6 years. At the same time in the training courses of each cycle there is the basic part (compulsory for all higher education institutions), variable part (established by the higher education institution) and the disciplinesof studentchoice [12].

\section{Materials and Methods}

In this section we define the methods of research and its theoretical and methodological approaches.

In the article, innovative aspects of educational dynamics in modern higher education are considered from the point of view of the methodology and the conceptual-categorical 
apparatus of the sciences of social and humanitarian cycle (jurisprudence and sociology in the construction field). The authors deal with the social issues of architecture and construction, give examples of innovative methods of erection of buildings, methods of visual accentuation of urban buildings, which are used by modern builders and architects, students of higher educational institutions of construction profilecomprehend these methods. The method for identifying urban sectors and needs of citizens living in different areas of a megacity, serves as an auxiliary technique in the framework of the analysis proposed in the article. The methodological principles that determine the educational processes in the university are investigated. Taken into account the methods used in modern higher school and connected with the introduction, as we said above, of the competence approach and the rejection of the subject-oriented(theoretically-oriented) approach [13].

The article mentions innovative educational technologies (competence approach, hourly credit system) that contribute to the formation of a qualified specialist in the conditions of modern higher school.

Having the trainingof specialists in high-rise construction as the subject of the article, the authors take into account the methods of erecting multi-storey houses that are being studied at civil engineering training centers. High-rise construction of residential buildings requires modern technologies in construction: from the use of nano-materials to the introduction of new generation equipment, from logistics to the specifics of training of construction personnel.

The authors have already analyzed the reaction of Russian higher educational institutions preparing civil engineers for educational reforms. The materials presented here are related to the response of students of the Moscow State (National Research) University of Civil Engineering to the conversion.Based on the data ofsurveys held at the educational institution of the construction profile (about the survey in the university, see [14]) and the analysis of the curricula of the bachelor's and master's degrees [15], the authors conclude that the system of training of construction engineers has reacted to the market demand of specialists in this field, promptly working out work programs for training, in accordance with the requirements of FSES 3++, as the initiators of reform are sure, highly qualified and popular specialists, actively innovating in the Russian construction branch.Such innovation in the educational process was appreciated by those who chose the profession of a builder. It causes a heightened interest not only among entrants, but also among those students who have graduated from the Bachelor's degree of ICC profile and already receive master's degree, they seek to master a new specialization (profile) for them in construction.

The educational standards applied in the training specialists in the field of high-rise construction allow not only to modernize educational programs aimed at building high-rise constructions from scratch, but also to develop a scientific approach to strengthening or restoring dilapidated buildings of high storey. After carrying out a number of construction works using innovative construction technologies, the buildings of the industrial era will be able to serve a fairly long period. It is also important to train building maintenance engineers ("Construction Technologies" profile) to use industrial buildings for nonresidential premises, where today offices of firms are usually located.

The new specialties that appear in Russian universities today, in addition to the name "industrial and civil construction", are often complemented by definitions of "innovative", "high-rise", "unique", "high-tech", etc., depending on the level of training being introduced.

In thisarticle the authors use sociological and general scientific methods of data analysis. The sociological data was obtained through a distribution questionnaire. The survey was conducted in 2017. The respondents were 100 students of 2-3 courses of the ISA Institute - a division of the Moscow State (National Research) University of Civil Engineering. The study was conducted in March-April 2017. 


\section{Results}

We will get acquainted with the assessments of the reforms of the construction education given by students studying in the specialties of high-rise construction. In the survey conducted among young people who chose the future specialty of civil engineers, the authors of the article obtained the results given below in this section.

To the question "What does the concept of hourly credit mean?", the respondents' answers were distributed as follows: only $3 \%$ of respondents were familiar with the concept, and the overwhelming majority, i.e. $93 \%$, could not explain what it is, and $4 \%$ of respondents made an attempt to determine the "hourly credit", though unsuccessful.

But in accordance with the latest innovations, according to the ECTS, hourly credit (Carnegie's credit) means the same as the credit unit, equal to 36 academic hours. This is a credit awarded to a learner for one course attended by a higher education institution. One academic year in European countries is equal to 60 ECTS-credits. For bachelors, the total amount is 180 to 240 ECTS-credits, and masters score 300 ECTS-credits.

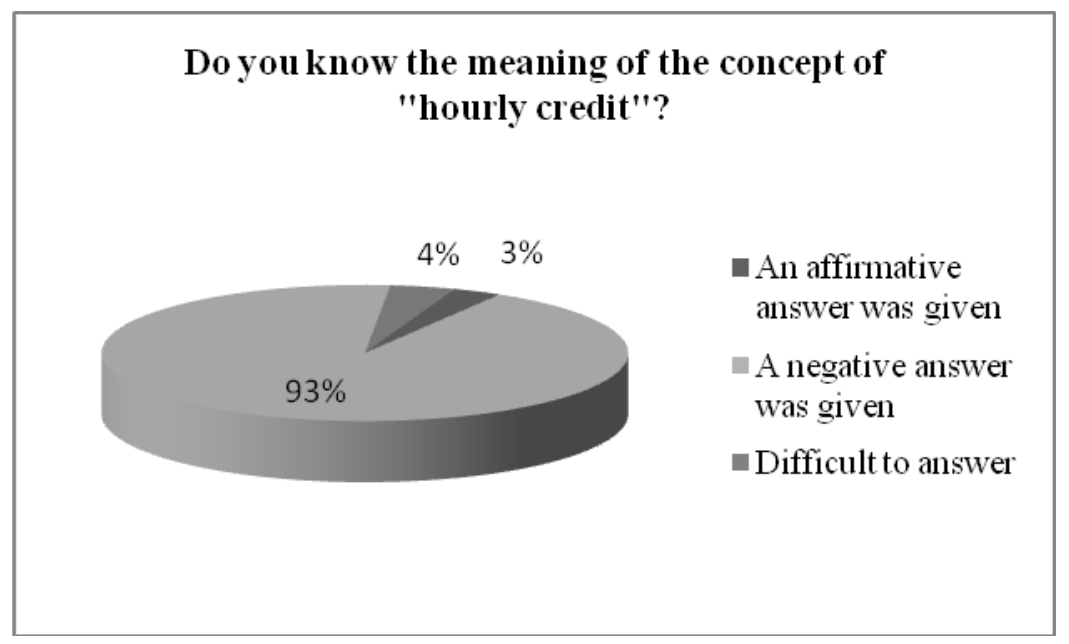

Fig 1. Results of the survey of the students of the construction university on the hourly credit.

Some questions related to the level of the training of future high-rise builders. The important aspect of training a specialist in the field of high-rise construction is the psychological training. It is important to train a person for work in a team, to develop qualities that will enable him to perform the functions of an engineer and manager. The question about the respondents' internal confidence in the level of their training was put: "Will you feel like a specialist after completing Bachelor's degree studies?" The opinions on the level of training, given by the students at this stage, are divided, as can be seen in the diagram below: 


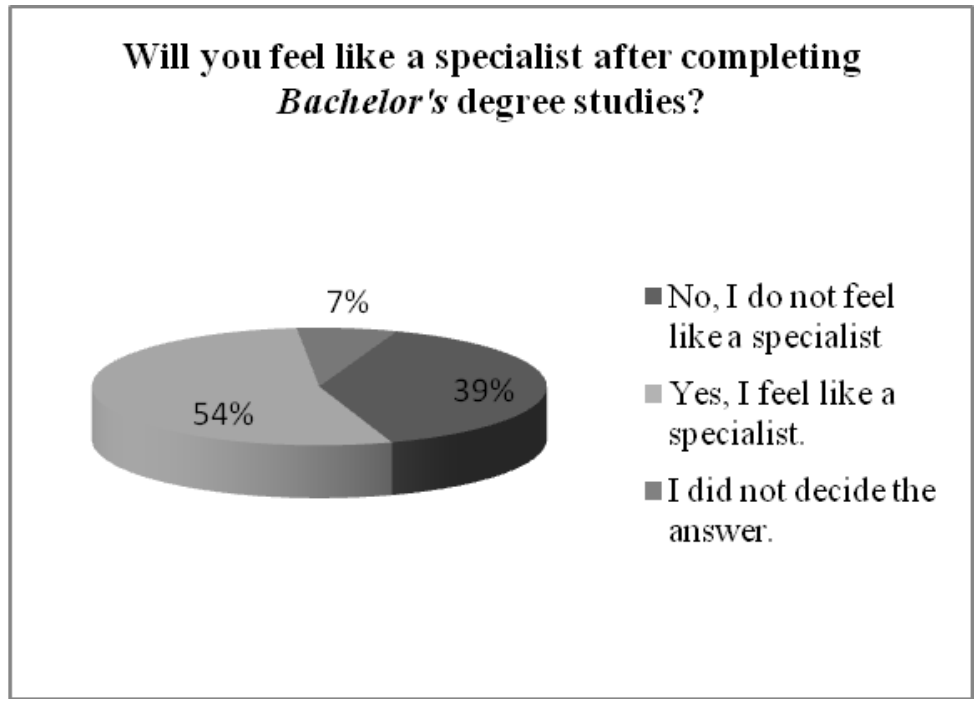

Fig 2.The results of processing the respondents' answers to the question: "Will you feel like a specialist after completing Bachelor's degree studies?"

At the same time, the majority of respondents acknowledge the need for further training of high-construction engineers in the magistracy. The survey notes the unity of views of young professionalsin this issue. The absolute majority seeks to continue their education in the magistracy. See the diagram in Fig 3:

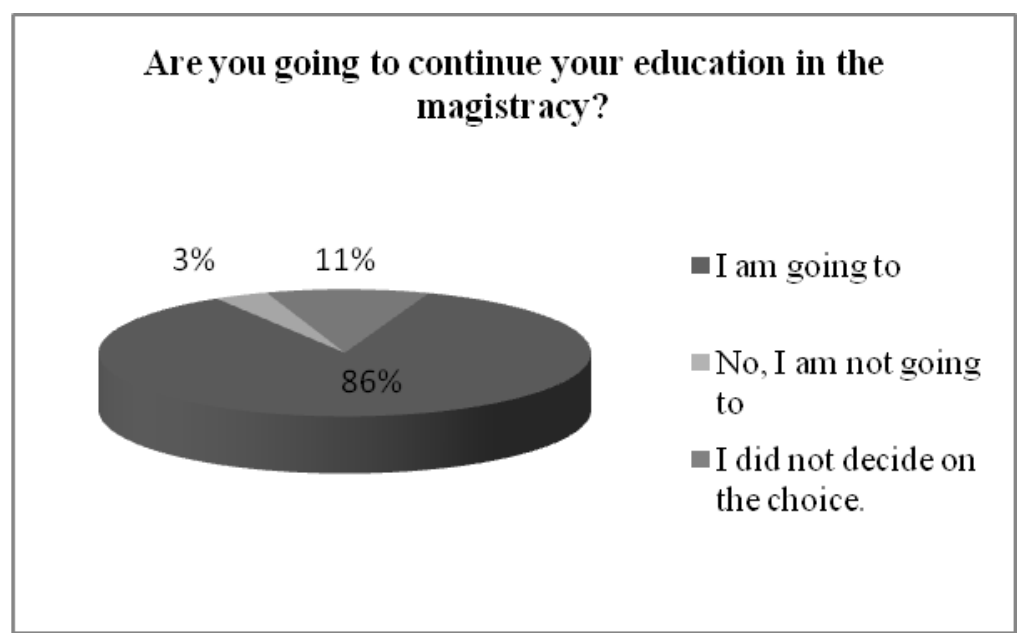

Fig 3. The results of processing the answers of respondents to the question: "Are you going to continue your education in the magistracy?"

\section{Discussion}

In this section, we highlight the discussion issues that our study has revealed. It is known that modern city is a space of application of social innovations. In the architectural and planning environment of a megacity, not only the most courageous innovative architectural projects that are aimed at satisfying the growing needs of modern citizens are being 
implemented.In addition, social experiments are being conducted aimed at overcoming the contradictions and conflicts between different groups of urban population.Is it necessary for a future specialist in high-rise construction to know the laws of social life, to be theoretically aware in matters of social innovation? On this seemingly rhetorical question, there are different points of view. "Undoubtedly yes", say some experts, and cite in this connection the arguments of the kind that the authors have placed above.After all, atthe present time the decision to place certain skyscrapers within a city is made on the basis of polls. The opposite view is that it is necessary to educate a competitive specialist, a highrise constructionengineer, a narrow connoisseur of construction mechanics and materials science, engineering design, etc. This position is shared not only by students, but also by some teachers of construction universities. It is supported by the rejection of the subject approach in favor of competence one. Those who advocate the rejection of social and psychological disciplines proceed from the requirement of training a narrow professional who, if necessary, can and should turn to the services of a sociologist, psychologist or jurist. The survey carried out by the authors of the article reflects the level of tension in discussion on this issue held inside the State construction university. The distribution of respondents' answers to the question "Do modern engineers need knowledge in the field of sociology of a city?" we can see in the diagram (Fig. 4):

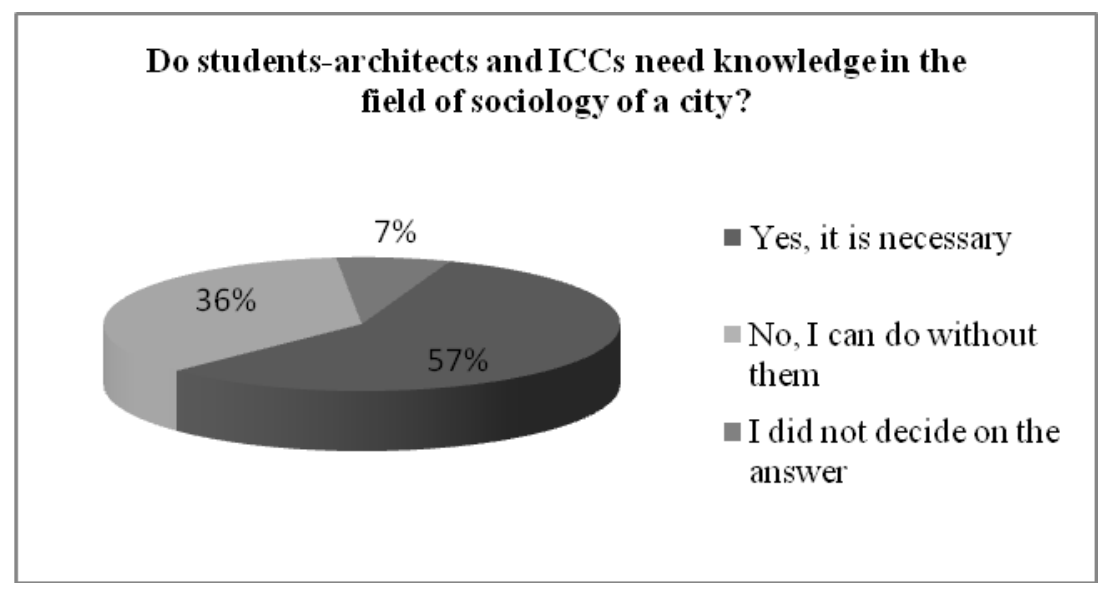

Fig 4. Theresultsofprocessingrespondents' answerstothequestion:«Do students-architects and ICCsneed knowledge in the field of sociology of a city?»

Approximately the same results we get on the question: "Do architects and ICCs need knowledge in the field of psychology"?The proportion of affirmative answers to this question is $7 \%$ higher than in the previous question (see Fig 5): 


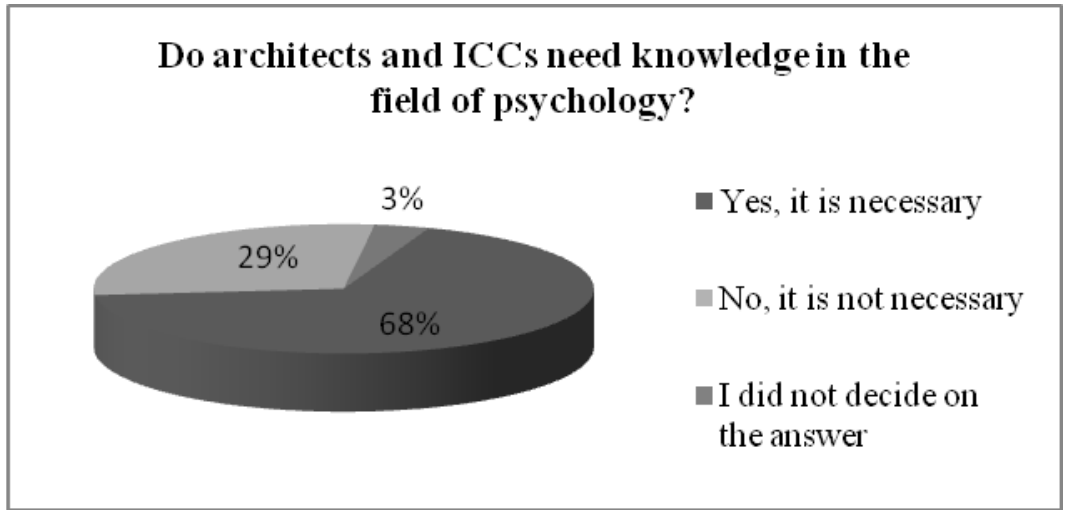

Fig 5. Theresultsofprocessingrespondents' answerstothequestion:«Do architects and ICCsneed knowledge in the field of psychology?»

The results of the analysis of the answers to the question: "Do students need to know the legal side of city planning and architecture?" turned out to be different (Fig 6). The overwhelming majority recognize the importance of legal regulation of the activities of city planners and architects. After all, jurisprudence helps to learn the laws that regulate city planning activity:

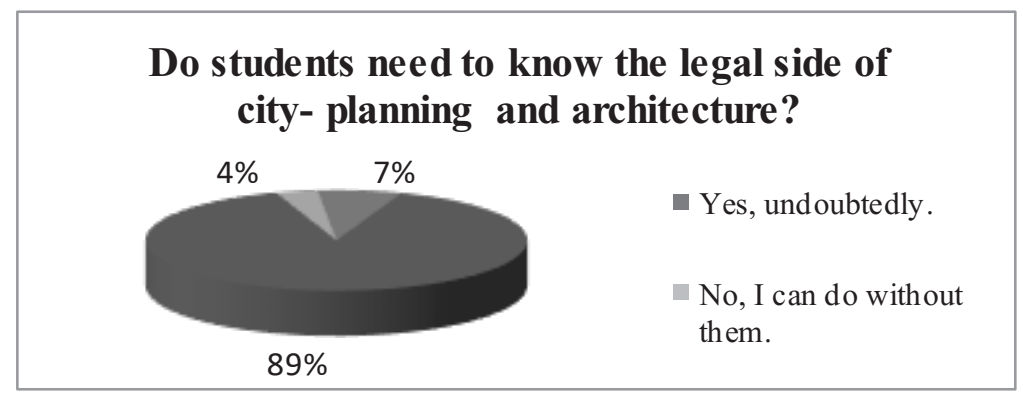

Fig6. Theresultsofprocessingrespondents' answerstothequestion: «Do students need to know the legal side of city-planning and architecture?»

\section{Conclusions}

Summarize. The dissemination and introduction of new scientific knowledge in the construction industry, conditioned by the processes of economic development, improvement of construction technologies predetermine the emergence of new training directions and profiles. The natural consequence of technical progress, changes in the parameters of life of a modern citizen, in the dynamics of pedagogical and scientific thought is the introduction of programs of a two-level system of education - Bachelor's and Master's programs.

In the context of these innovations, the specialization and professionalization should be regarded as a kind of social and economic order of the society for training highly qualified specialists. Specialization in the field of training of civil engineers in general is due to the features and direction of economic development. The survey carried out by the authors of the article showed how much the consciousness of students, trained in one of the leading 
Russian construction universities, has been prepared for challenges in the field of education and in the field of their future engineering activities [16].

As in the case of educational credit, we have found that misunderstanding of the purposes of educational reforms generates a negative attitude towards some educational innovations. Students fear that a practice-oriented approach is introduced at the expense of obtaining theoretical knowledge, a solid acquaintance with theoretical knowledge distinguished the domestic construction education.

On the other hand, the desire to expand the range of professional knowledge is typical for the majority of respondents planning to enter the magistracy. At the same time, on the issue of acquaintance of construction students with disciplines that make it possible to master general cultural competences, the students' opinion was not formed.This is indicated by the scatter of answers received from respondents during the survey.

\section{References}

1. E. Romanova, Studying of Innovative Qualities at Experts in the Field of Production and Use of Eco-Friendly Construction Materials, Materials Science Forum,871, 132 (2016)

2. M.G. Leontev, MATEC Web of Conf. 73 (2016)

3. S.A. Medvedev, The Bologna Process. Russia and Globalization, the Bologna Process and its Implications for Russia (M.: RETSEP, 2005)

4. I. P. Pryadko, I.M.Lebedev, MATEC Web of Conf. 106, 09015(2017)

5. M. G. Leontev, MATEC Web Conf., 106, 09005(2017)

6. E.S. Dudar', Bulletin of PNIPU. Construction and Architecture. 1, 72(2014)

7. L.V. Makovskiy, D.V.Polyakov,Science and technology in the road industry. 2, 206(2016)

8. N.G. Miloradova, A.D. Ishkov,Procedia Engineering 117, 246 (2015)

9. M.A. Ivanova, Proceedings of the XVII International Interuniversity scientific and practical conference (M.: MGSU, 2014)

10. A.D. Ishkov, M.Y. Mishlanova, K.P. Grabovyi, International Journal of Applied Engineering Research11(3) 1676 (2016)

11. N.G. Miloradova, A.D. Ishkov, MATEC Web Conf. XV International Conference "Topical Problems of Architecture, Civil Engineering, Energy Efficiency and Ecology - 2016"73 07003 (2016)

12. URL: http://fgosvo.ru/uploadfiles/fgosvob/080301.pdf

13. L.V. Vlasenko, I.P. Pryadko, Integration, partnership, and innovation in construction science and education.1( 2012)

14. L.V. Vlasenko, Organization and conduct of educational sociological researches(M.: MGSU, 2011)

15. Educational activity and training of scientific personnel,AccessMode: http://mgsu.ru/science/Obraz_deyatelnost/

16. I.Pryadko,A.Ishkov, Procedia Engineering165,1162 (2016) 